\title{
Targeted Preventive Maintenance of Pharmaceutical Equipment
}

\author{
Hao Yinghua, Liang Yi* \\ Email address: \\ 914083673@qq.com (Hao Yinghua), ly606@sohu.com (Liang Yi) \\ *Corresponding author
}

School of International Pharmaceutical Business, China Pharmaceutical University, Nanjing, China

\section{To cite this article:}

Hao Yinghua, Liang Yi. Targeted Preventive Maintenance of Pharmaceutical Equipment. Journal of Drug Design and Medicinal Chemistry. Vol. 4, No. 2, 2018, pp. 10-15. doi: 10.11648/j.jddmc.20180402.11

Received: April 24, 2018; Accepted: June 5, 2018; Published: July 4, 2018

\begin{abstract}
To study effective management mode for preventive maintenance of equipment in pharmaceutical enterprises. Different pharmaceutical equipment has different importance in the producing process, so maintenance to each equipment should be different. A targeted maintenance reqiures to classify equipment and its components. To this aim, with help of assessment tools such as System Impact Assessment(SIA), Component Criticality Assessment(CCA) and deision-making grip, the specific targeted maintenance plan can be made and then implement it. Check the effect and feed back the problems. According to assess result of SIA \& CCA, and deision-making grip, Pharmaceutical equipment can be classified into key equipment, important equipment and insignificant equipment. Components of equipment can be divided into two levels, critical and non-critical. For critical components of key equipment, comprehensive maintenance is needed. Maintenance of non-critical parts of key equipment and critical parts of important equipment should be paid great attention to. As for non-critical parts of important equipment and insignificant equipment, daily maintenance is enough. Such maintenance plan makes a distinction between the important equipment and the lesser ones. Through targeted management, preventive maintenance effect can be improved.
\end{abstract}

Keywords: Pharmaceutical Equipment, Preventive Maintenance, Decision-Making Grip, GMP

\section{Introduction}

Pharmaceutical equipment is the material basis of drug production. It is an key element influencing business efficiency and drug quality. A single "Breakdown Maintenance" mode cannot meet the drug quality requirements. [1] The revised version of " Good Manufacturing Practice"(GMP) in China has clearly proposed that equipment preventive maintenance plan and procedures must be formulated. United States's cGMP also has some regulations about maintenance, such as "Equipment and utensils shall be cleaned, maintained, and, as appropriate for the nature of the drug, sanitized and/or sterilized at appropriate intervals to prevent malfunctions or contamination that would alter the safety, identity, strength, quality, or purity of the drug product beyond the official or other established requirements". [2] Both two GMPs all emphasize the idea of "prevention first". Relatively weak equipment management consciousness, meanwhile, a large number of equipment in pharmaceutical enterprised, especially API production enterprises with insufficient personnel and low professional competence have lead preventive maintenance to become a mere formality in many enterprises. [3] To this end, the author puts forward a new preventive maintenance mode. Based on PDCA cycle, with the help of assessment tools like System Impact Assessment (SIA), Component Criticality Assessment (CCA) and decision-making grip, the equipment and components can be classified to formulate a hierarchical management mode.

\section{Theoretical Basis of Targeted Maintenance Management}

One enterprise usually has dozens or even hundreds of devices, each of which plays a different role in the production process. Some of these equipments are frequently used, while others are used occasionally with less importance. They also operate in different ways, some with high reliability and others may with frequent breakdowns. At present, most 
pharmaceutical companies donot carry out targeted equipment maintenance according to actual situation of each equipment, which results in insufficient maintenance or overmaintenance. Therefore, it is necessary to distinguish the equipment and carry out targeted maintenance.

\subsection{Based on Equipment Importance}

Generally, the larger the enterprise scale, the more equipment it has. Large and medium-sized enterprises usually have a large number of equipment. Different equipment plays a different role in the process of production, so the maintenance method should be different. When developing the maintenance strategy of each equipment, the importance of equipment should be classified first.
In addition to the production equipment, the pharmaceutical enterprise also involves utilities (such as HVAC) and auxiliary equipment (such as vacuum pump). Obviously, the importance of different equipment is different in the process of drug production. They can be divided into key equipment, important equipment and insignificant equipment through SIA. $[4,5]$ According to the general process of SIA (figure 1), when evaluating one equipment, answer No.1 No.7 questions in table 1. If there is one or more "Yes", this equipment is seen as a key equipment. Otherwise, answer questions No.8 No.9, as long as thers is one "yes", the equipment is an important equipment. If all the questions in table 1 are answered "no", a common equipment shall be defined. Table 2 is an example of equipment classification in API enterprises.

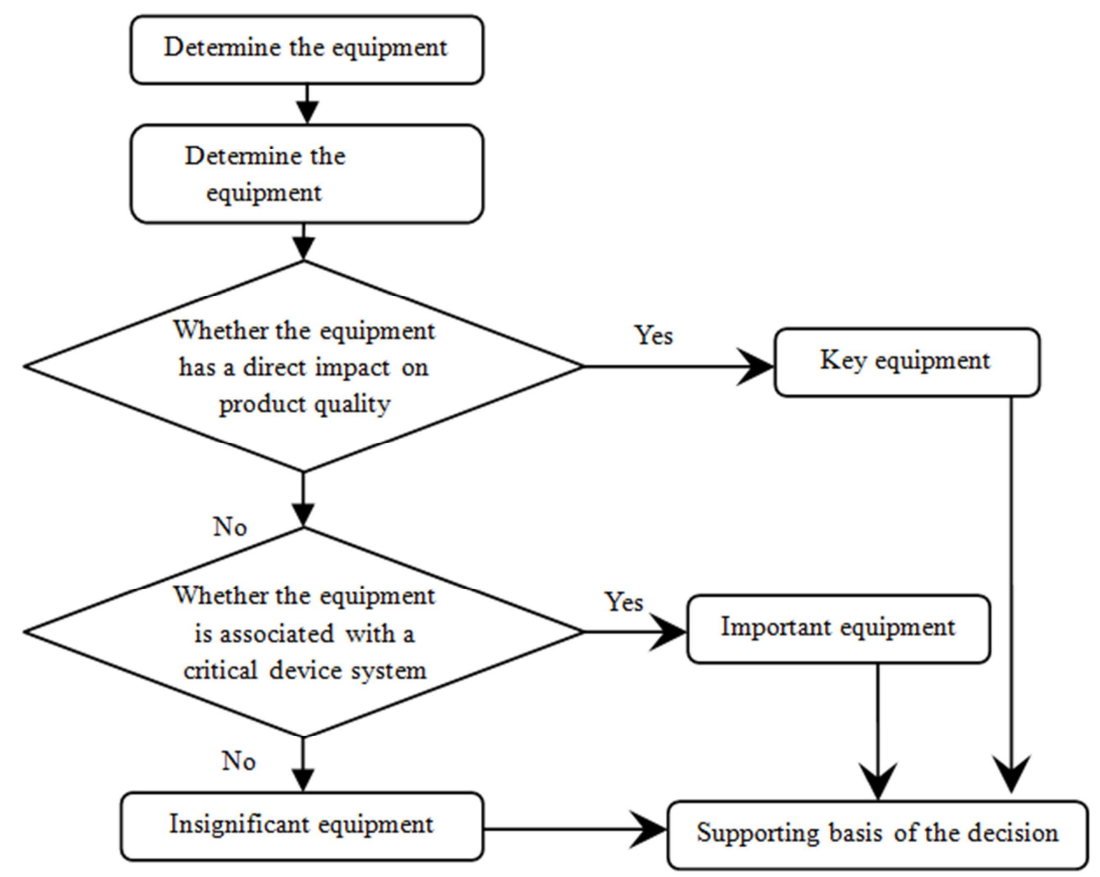

Figure 1. Flow chart of SIA.

\subsection{Based on Statistical Results of Equipment Failure Information}

Table 1. Question list of SIA.

\begin{tabular}{ll}
\hline No. & Questions \\
\hline 1 & $\begin{array}{l}\text { Whether the equipment is directly exposed to the product } \\
\text { Whether the equipment provides auxiliary materials, Whether it is } \\
\text { used for producing (or direct contact) some components, raw } \\
\text { materials or solvents that are in contact with the process }\end{array}$ \\
3 & $\begin{array}{l}\text { Whether the equipment is used for cleaning or sterilization } \\
\text { Whether the equipment is used to protect the product character, such } \\
\text { as product safety, concentration, quality, etc. }\end{array}$ \\
5 & $\begin{array}{l}\text { Whether the equipment generates data for receiving or rejecting the } \\
\text { product and whether it is used to evaluate the disposition of the } \\
\text { product }\end{array}$ \\
6 & $\begin{array}{l}\text { Whether the equipment afftec the process control system linked to } \\
\text { product safety, characteristic and concentration. }\end{array}$ \\
7 & $\begin{array}{l}\text { Whether the equipment is used for controlling, monitoring and } \\
\text { alarming important environmental conditions. }\end{array}$ \\
8 & $\begin{array}{l}\text { Whether the equipment provides utilities or some function for a } \\
\text { critical equipment. } \\
\text { Whether the equipment affects the performance of a key equipment. }\end{array}$ \\
\hline
\end{tabular}

Table 2. Equipment classifications in API enterprises.

\begin{tabular}{lll}
\hline System description & $\begin{array}{l}\text { SIA assessment } \\
\text { resuilts }\end{array}$ & $\begin{array}{l}\text { Equipment } \\
\text { classification }\end{array}$ \\
\hline Reactor & YNNYNYN & Key equipment \\
Centrifuge & YNNNNYN & Key equipment \\
Vacuum dryer & YNNNNYN & Key equipment \\
Pulverizer & YNNNNYN & $\begin{array}{l}\text { Key equipment } \\
\text { Vacuum pump }\end{array}$ \\
NNNNNNNYY & Important equipment \\
Nitrogen production & NYNNNNN & Key equipment \\
equipment & NNNNNNNYY & Important equipment \\
HVAC system & NNYNNNY & Key equipment \\
Purified water system & NYYNNNN & Key equipment \\
Elevator system & NNNNNNNNN & Insignificant equipment \\
Fire fighting equipment & NNNNNNNNN & Insignificant equipment \\
\hline
\end{tabular}

Note: Some equipment has different uses in different enterprises such as nitrogen generating equipment, so the evaluation may vary in this way. This table is just for reference.

According to historical operation data of each equipment, 
some equipment with the same characteristics can be picked out by some specific ways. Then targeted maintenance can be implemented to these devices with the same traits. The decision-making grid is one of the tools that can be used to distinguish different sets of devices. It takes the decision variable failure frequency as ordinate axis and failure time as abscissa axis, and then quantify them based on the statistic failure data. Choose a certain quantized interval to rank the two decision variables and then form the grid (figure 2). [6] In this grid, each squares represents a collection of devices with the same characteristics. Different equipment will fall into a grid area after decision. Equipment in the same area can be seen as the same kind.

\begin{tabular}{|c|c|c|c|c|}
\hline \multirow{4}{*}{$\begin{array}{c}\text { Failure } \\
\text { frequency }\end{array}$} & \multicolumn{4}{|c|}{ Downtime } \\
\cline { 2 - 5 } & Low & Sow 1 & Middle & High \\
\cline { 2 - 5 } & Middle & Set 2 & Set 5 & Set 7 \\
\cline { 2 - 5 } & High & Set 3 & Set 6 & Set 9 \\
\hline
\end{tabular}

Figure 2. Decision-making grip map.

The following method can be used in decision variable quantification: for each device, extracted the data related to decision variables from historical database. Accumulate the failure time of each device. Respectively sort the equipment failure frequency and the cumulative failure time in descending order. After sorted, accumulate the parameter values from big to small until the cumulative value is more than $80 \%$ of the sum of all parameter values. [7] Record the devices and their corresponding parameter value. For examole, based on the failure data in table 3, a decision-making grid (figure 3)can be established using the method described above. The 3 levels of failure time can be set as "low"-(0, 20), "middle"-(20, 40), "high"-(40, 60) and 3 levels of failure frequency can be set as "low"-(0, 10), "middle"-(10, 20), "high"-(20,30). As showed in figure 3 , the equipment closer to the lower right corner have a worse reliability, and those closer to the top left corner has a better reliability. As a result, those equipment at the bottom right corner can be seen key or important device which meed to be paid more attention in the maintenance.

\subsection{Equipment Component Grading}

Conduct importance assessment of components in key equipment and important equipment, using CCA or risk assessment tools. CCA divided the components based on their influence on product quality and production process. First, list all components or functional units of each equipment and then answer 6 questions listed in table 4. [4] As long as there is one answer is "yes", the component will be graded as key components. Otherwise, it will be seen as non-critical part. Table 5 is CCA evaluation results for purified water system components. [8] In addition, risk assessment tool FMEA can be used[5], after all parts in the equipment listed, evaluate and analyze possible failure modes, and give a mark for severity(S), detectable degree(D) and possibility(P) of each failure mode, calculate the risk priority number $(\mathrm{RPN},=\mathrm{S} * \mathrm{D}$ * P). The greater the RPN value indicates the higher risk which means the component is more critical. The advantage of FMEA analysis is that it can predict the failure mode of components and make maintenance measures in advance.

Taleb 3. Failure data of equipment.

\begin{tabular}{lll}
\hline Name & Failure frequency & Downtime \\
\hline Equipment 1 & 5 & 43 \\
Equipment 2 & 2 & 40 \\
Equipment 3 & 3 & 8 \\
Equipment 4 & 9 & 12 \\
Equipment 5 & 8 & 21 \\
Equipment 6 & 17 & 5 \\
Equipment 7 & 20 & 32 \\
Equipment 8 & 21 & 50 \\
Equipment 9 & 1 & 28 \\
Equipment 10 & 25 & 17 \\
Equipment 11 & 24 & 58 \\
Equipment 12 & 29 & 3 \\
Equipment 13 & 11 & 34 \\
Equipment 14 & 14 & 25 \\
\hline
\end{tabular}

\begin{tabular}{|c|c|c|c|c|}
\hline \multirow{4}{*}{} & \multicolumn{4}{|c|}{ Downtime } \\
\hline \multirow{4}{*}{$\begin{array}{c}\text { Failure } \\
\text { frequency }\end{array}$} & Low & Equipment & Equipment & Equipment \\
\cline { 2 - 6 } & Middle & Equipment 6 & Equipment & -- \\
& & & $7,12,14$ & \\
\cline { 2 - 5 } & & Equipment & -- & Equipment \\
& High & 10,12 & & 8,11 \\
\hline
\end{tabular}

Figure 3. Decision-making grip map

\section{Targeted Maintenance Plan}

The equipment maintenance plan at least includes the maintenance object, maintenance method, maintenance cycle and other aspects. Maintenance methods include daily maintenance, spot check, cycled recondition and irregular improvement, etc. Daily maintenance is mainly carried out by the operator, including cleaning and lubrication before or after equipment operation; Spot check is a triple check mechanism formed by operators, administrators and maintainers. [1] Through fixed-point inspections, clearly know equipment technical status and find hidden danger timely. The analysis of periodic data is the basis of cycled recondition; The cycled recondition can be divided into minor repairs and overhaul, which is operated by professional maintainers aimed for renewing equipment state and eliminating the hidden trouble; Irregular partial improvement can be understood as performance improvements. maintenance personnel, and management personnel usually participate in it. 
Table 4. Question list of CCA.

\begin{tabular}{ll}
\hline No. & Questions \\
\hline 1 & $\begin{array}{l}\text { Whether the component is used to control a key process parameter. } \\
2\end{array}$ \\
$\begin{array}{l}\text { Whether the normal operation or control, failure or alarm of the } \\
\text { component has a direct impact on the quality of the product. }\end{array}$ \\
3 & $\begin{array}{l}\text { Whether the information generated by the component is recorded as } \\
\text { part of the batch record, batch release data, or other GMP related } \\
\text { files. }\end{array}$ \\
4 & $\begin{array}{l}\text { Whether the component is in direct contact with the product, product } \\
\text { ingredient or internal packaging material of the product }\end{array}$ \\
5 & $\begin{array}{l}\text { Whether the component is used to control the key process } \\
\text { parameters affecting product quality }\end{array}$ \\
6 & $\begin{array}{l}\text { Whether the component is used to create or maintain a system } \\
\text { critical state }\end{array}$ \\
\hline
\end{tabular}

The maintenance cycle is mainly focused on cycled recondition, and many scholars have studied it. The maintenance period of traditional cycled recondition is always the same, which tends to increase maintenance costs and equipment performance destory. [9] According to the equipment failure rule (early failure period, accidental failure period and wearing malfunction period)[10], the maintenance period of equipment should be adjusted in real time according to the working age. Enterprises should determine the best minor repair or overhaul cycle of each device under lowest cost or maximum availability principle[11], according to the specific situation of equipment. Generally, the maintenance period of key equipment should be shorter than that of important equipment, and the maintenance period of key components should also be shorter than that of non-critical parts. "Condition-based maintenance" will be the future development tendency. [9]

Table 5. Component classification of purified water system.

\begin{tabular}{|c|c|c|c|}
\hline Components & Description & Assessment results & Criticality \\
\hline Raw water tank & Store raw water & NNNNNN & $\mathrm{N}$ \\
\hline Liquid level sensor & Monitor the liquid level in the raw water tank & NNNNNN & $\mathrm{N}$ \\
\hline Multi-media filter & Remove solid particles from raw water & NNNNNN & $\mathrm{N}$ \\
\hline Pressure gauge & Monitor multi-media filter inlet pressure & NNNNNN & $\mathrm{N}$ \\
\hline Activated carbon filter & Remove residual chlorine and organic matter from raw water & NNNNNN & $\mathrm{N}$ \\
\hline Pressure gauge & Monitor activated carbon filter inlet pressure & NNNNNN & $\mathrm{N}$ \\
\hline Flowmeter & Monitor the saltwater flow of softener & NNNNNN & $\mathrm{N}$ \\
\hline Pressure gauge & Monitor the inlet pressure of softener. & NNNNNN & $\mathrm{N}$ \\
\hline Security filter & Water inlet filtration of RO unit & NNNNNN & $\mathrm{N}$ \\
\hline RO membrance & Remove ions from water & NYNYNY & Y \\
\hline Pressure gauge & Show operation pressure of RO unit. & NNNYNN & $\mathrm{Y}$ \\
\hline Heat exchanger & Used for disinfection for RO and EDI units & NYNYNY & $\mathrm{Y}$ \\
\hline High pressure pump & Blower pump for RO and EDI units & NNNYNY & $\mathrm{Y}$ \\
\hline $\mathrm{pH}$ probe & Control the $\mathrm{pH}$ of inlet in $\mathrm{RO}$ unit. & NYNYNY & $\mathrm{Y}$ \\
\hline Flowmeter & Monitor the water flow in $\mathrm{RO}$ unit & NNNYNY & $\mathrm{Y}$ \\
\hline Pressure gauge & Monitor the operation pressure of EDI unit & NNNYNN & $\mathrm{Y}$ \\
\hline Conductivity sensor & Monitor the conductivity of EDI outflow & NYNYNY & $\mathrm{Y}$ \\
\hline Flowmeter & Monitor the water flow in $\mathrm{RO}$ unit & NNNYNY & Y \\
\hline Cleaning tank & Store cleaning water & NNNNNN & $\mathrm{N}$ \\
\hline Cleaning pump & Cleaning water cycle & NNNNNN & $\mathrm{N}$ \\
\hline Pressure gauge & Monitor pressure of cleaning & NNNNNN & $\mathrm{N}$ \\
\hline PLC control system & Control unit of water producing & NNYNNY & $\mathrm{Y}$ \\
\hline Purified water tank & Store purified water & NYNYNN & $\mathrm{Y}$ \\
\hline Sanitary pump & Transport purified water & NYNYNN & $\mathrm{Y}$ \\
\hline Ultraviolet sterilizer & Purified water sterilization & NYNNNY & $\mathrm{Y}$ \\
\hline Distribution pipes and valves & Connect and control the outflow & NNNYNY & Y \\
\hline
\end{tabular}

Table 6. Preventive maintenance plan of purified water system.

\begin{tabular}{|c|c|c|c|c|c|c|c|}
\hline \multirow[b]{2}{*}{ Equipment } & \multirow[b]{2}{*}{ Class } & \multirow[b]{2}{*}{ Component } & \multirow[b]{2}{*}{ Criticality } & \multicolumn{4}{|l|}{ Maintenance plan } \\
\hline & & & & Daily maintenance & Spot check & $\begin{array}{l}\text { Cycled } \\
\text { recondition }\end{array}$ & $\begin{array}{l}\text { Irregular } \\
\text { improvement }\end{array}$ \\
\hline \multirow{12}{*}{$\begin{array}{l}\text { Purified } \\
\text { water system }\end{array}$} & \multirow{12}{*}{$\begin{array}{l}\text { Key } \\
\text { equipment }\end{array}$} & Raw water tank & \multirow{6}{*}{ Non-critical } & $\sqrt{ }$ & $x$ & $\sqrt{ }$ & $\times$ \\
\hline & & Liquid level sensor & & $\sqrt{ }$ & $x$ & $\sqrt{ }$ & $x$ \\
\hline & & Multi-media filter & & $\sqrt{ }$ & $x$ & $\sqrt{ }$ & $x$ \\
\hline & & Raw water pump & & $\sqrt{ }$ & $x$ & $\sqrt{ }$ & $x$ \\
\hline & & Pressure gauge & & $\sqrt{ }$ & $x$ & $\sqrt{ }$ & $x$ \\
\hline & & ...... & & & & & \\
\hline & & RO membrance & & $\sqrt{ }$ & $\sqrt{ }$ & $\sqrt{ }$ & $\sqrt{ }$ \\
\hline & & Pressure gauge & & $\sqrt{ }$ & $\sqrt{ }$ & $\sqrt{ }$ & $\sqrt{ }$ \\
\hline & & Heat exchanger & & $\sqrt{ }$ & $\sqrt{ }$ & $\sqrt{ }$ & $\sqrt{ }$ \\
\hline & & High pressure pump & Critical & $\sqrt{ }$ & $\sqrt{ }$ & $\sqrt{ }$ & $\sqrt{ }$ \\
\hline & & $\mathrm{pH}$ probe & & $\sqrt{ }$ & $\sqrt{ }$ & $\sqrt{ }$ & $\sqrt{ }$ \\
\hline & & Conductivity sensor & & $\sqrt{ }$ & $\sqrt{ }$ & $\sqrt{ }$ & $\sqrt{ }$ \\
\hline
\end{tabular}




\begin{tabular}{|c|c|c|c|c|c|c|c|}
\hline \multirow{4}{*}{ Equipment } & \multirow{4}{*}{ Class } & \multirow[b]{2}{*}{ Component } & \multirow{4}{*}{ Criticality } & \multicolumn{4}{|l|}{ Maintenance plan } \\
\hline & & & & Daily maintenance & Spot check & $\begin{array}{l}\text { Cycled } \\
\text { recondition }\end{array}$ & $\begin{array}{l}\text { Irregular } \\
\text { improvement }\end{array}$ \\
\hline & & Flowmeter & & $\sqrt{ }$ & $\sqrt{ }$ & $\sqrt{ }$ & $\sqrt{ }$ \\
\hline & & $\begin{array}{l}\text { PLC control system } \\
\text {....... }\end{array}$ & & $\sqrt{ }$ & $\sqrt{ }$ & $\sqrt{ }$ & $\sqrt{ }$ \\
\hline
\end{tabular}

Note: "N"means that the maintenance mode in corresponding column is needed, while "×"means not needed. The maintenance circle is not declared in this table because each enterprise should set up their own reasonable circle according to equipment condition and enterprise capability.

According to evaluation results of equipment and component, combined with different methods and maintenance cycle, equipments actually need different levels of maintenance. As showed in figure 4, the key components of key equipment is the emphasis, which need a comprehensive maintenance. Those key components of important equipment should also be focused on. Table 6 is a specific preventive maintenance plan based on the assessment results of purified water system.

\begin{tabular}{c|c|c|}
\cline { 2 - 3 } Key equipment & $\begin{array}{c}\text { Comprehensive maintenance } \\
\text { (Daily maintenance }+ \text { spot } \\
\text { check +cycled recondition }+ \\
\text { irregular improvement) }\end{array}$ & $\begin{array}{c}\text { Focused maintenance } \\
\text { (Daily maintenance +cycled } \\
\text { recondition) }\end{array}$ \\
\cline { 2 - 3 } $\begin{array}{c}\text { Important } \\
\text { equipment }\end{array}$ & $\begin{array}{c}\text { Focused maintenance } \\
\text { (Daily maintenance +cycled } \\
\text { recondition) }\end{array}$ & Daily maintenance \\
\cline { 2 - 3 } $\begin{array}{c}\text { Insignificant } \\
\text { equipment }\end{array}$ & \multicolumn{2}{|c}{ Daily maintenance } \\
\cline { 2 - 3 } & \multirow{2}{*}{ Critical components } & Non-critical components
\end{tabular}

Figure 4. Chart of targeted preventive maintenance of pharmaceutical equipment.

\section{Implementation, Check and Action of Preventive Maintenance Plan}

A reasonable plan is the premise to achieve the goal, and effective implementation is the realization step of the expected goal. According to the maintenance plan, the equipment department of pharmaceutical enterprises should develop the specific maintenance operating procedures for each equipment. Personnel is the principal part of the maintenance performing. Learning from idea of "Total Productive Maintenance (TPM)" [12], mobilize full participation to cultivate the consciousness of equipment.

management personnel, maintainer and equipment operator in equipment improvement and problem finding.

Checking phase is a connecting link between the preceding and the following. It is the feedback of the implementation effect. Enterprise can collect and analyze the equipment failure data every a month or a quarter and then timely give these information to equipment department and quality department to find maintenance effectiveness as well as the deviation in the execution. From this process, the successful experience or existing deficiencies will be found. The action period is the response to check results. It is a process of summarizing the analysis. At this stage, the enterprise should formulate written management system and operation procedures for equipment maintenance according to the quarterly or annually inspection results. For those failure to solve, Enterprise can put forward the improvement measures on this basis and then proceed to the next PDCA cycle until the problem is solved.

\section{Conclusion}

Equipment maintenance is a must work in pharmaceutical enterprises, and preventive maintenance management must rely on scientific methods. According to the characteristics of the pharmaceutical equipment and failure data, the pharmaceutical equipment are classified into different levels with different importance, so that a well-directed equipment maintenance system can be formed. Flexibly using it can effectively improve the efficiency and quality of equipment maintenance.

However, the application of the assessment tools such as SIA \& CCA and the maintenance level is no talways fixed. The enterprise should make the best maintenance plan related 
to specific issues. Meanwhile, the results assessed by SIA and CCA tools can always affected by subjectivity, more attention should be paid to avoid.

\section{References}

[1] Xu L. M., Tang H. X. and Dai Z. H. Discussion on Preventive Maintenance and Spot Check Management of Pharmaceutical Enterprises [J]. 2015, 86.

[2] FDA. CURRENT GOOD MANUFACTURING PRACTICE FOR FINISHED PHARMACEUTICALS [S]. 2016.

[3] Qian H. D., Cai X. C. Analysis of Pharmaceutical Equipment Management and Maintenance Methods [J]. Chemical management, 2015, 52-53.

[4] ISPE Baseline Pharmaceutical Engineering Guide Volume 5: Commissioning and Qualification [S]. 2000.

[5] ICH. ICH Q9: Quality Risk Development [S]. 2009.

[6] Ashraf W. Labib. A decision analysis model for maintenance policy selection using a CMMS [J]. Journal of Quality in Maintenance Engineering. 2004, Vol 10, 191-200.
[7] Wang J. Y. Multi-Attribute Decision Making Method of Equipment Maintenance Based on Fuzzy Theory [D]. Shanghai Jiao Tong University, 2011.

[8] Liang Y., Ding E. W. Appilication of CCA and FMEA in Risk Assessment of Pharmaceutical Purified Water Distribution System [J]. China Pharmacy, 2015, Vol 26, 1306-1308.

[9] Xu A. D., Yu H. B. and Guo Q. J. Conditon Based Equipment Maintenance: Research on CBM Technology [J]. Construction Machinery and Equipment, 2005, Vol 36, 9-13.

[10] Zhang C. X. Optimization of Preventive Maintenance Strategy for Equipment $[\mathrm{J}]$. Science and Technology Innovation Herald, 2015, 211-212.

[11] Deng P. and Liang Y. Study of Protective Maintenance of Pharmaceutical Equipment [J]. Pharmaceutical \& Engineering Design, 2011, Vol. 32, 49-53.

[12] Liu X., Jiao S. Q. Introduction of TPM Application in Management of Equipment Maintenance for Pharmaceutical Enterprise $[\mathrm{J}]$. Chemical and Pharmaceutical Engineering, 2014, Vol. 35, 38-41. 